\title{
A study on competition of hinterland in Zhejiang Province between Shanghai Port and Ningbo Port
}

\author{
Jia-bin $\mathrm{Li}^{*} \cdot \mathrm{Su}-\mathrm{Ho} \mathrm{Lee}^{* *}$ \\ * PhD Course, Korea Maritime University, Busan 606-791, Korea \\ ** Professor, Korea Maritime University, Busan 606-791, Korea
}

\begin{abstract}
Ningbo Port develops quickly in recent years and with the combination of Ningbo Port and Zhoushan Port, it becomes another important port in the Shanghai International Shipping center. Competition between the two biggest ports in this area can't be avoided. The goal of this paper is investigating the competence of port from two angles, which are spatial structure of the ports cluster and neighboring ports' attraction to cargoes at conjunct hinterlands.

The paper firstly uses the HHI index model and shift-share method to qualitatively and quantitatively analyze the data of container throughputs of ports in the shipping center, in order that investigates the spatial structure of ports cluster. Basing on above researches, the paper employs the location quotient to study Shanghai port and Ningbo port's hinterland distributions at Zhejiang province.

The conclusion of this study:( I)the ports cluster of the Shanghai International Shipping Center is highly centralized, and undergoes a porcess of first centralization then decentralization since the mid of 90s, last century. (2)Hinterlands of Shanghai port includes: Hangzhou, Jiaxing, Huzhou and Quzhou districts; Hinterlands of Ningbo port includes: Ningbo, Taizhou and Zhoushan districts.
\end{abstract}

Key words : Shanghai International Shipping Center; Port hinterland; Market share of cargoes

\section{Introduction}

The high-speed development of international trade is one of the most important sign of economic globalization. We can find that the growth rate of world international trade is more than the growth rate of world economy. As a major way of global logistics and an important factor of economic globalization, ocean transport becomes more and more important. Modern seaports have become critical nodes in complex logistics chains. Seaports that fail to establish themselves as key players in the optimization process unfolding within such logistics chains are in danger of 'missing the boat' and being disregarded as ports of call on international freight routes.

In an era of economic globalization ports are evolving rapidly from being traditional land/sea interface to providers of complete logistics networks. This means ports have to face many challenges due to unpredictable environmental changes and trends in the shipping, port and logistics industries. It is estimated that $90 \%$ of the world internationally traded goods are imported or exported by sea. And the container transportation has become the most important way to global trade.

As the rapid development of Asia-Pacific region's economy, the world economic center has been transferred into this area step by step. In terms of annual container throughputs, 9 Asian ports are ranked among the top10 container ports in the world and 6 of them are Chinese ports which rank second, third, forth, seventh, eighth and tenth respectively. Amongst Asian economies, the Chinese economy is regarded as the world's most fascinating in the modern era. The proportion of container transport is getting higher and higher and it is the future trend of ocean shipping development. So container transport is an important aspect in port competitiveness research.

In March 2001, the Fourth Session of the Ninth National People's Congress of the People's Republic of China approved "the Tenth Five-year Plan Outline of the Economic and Social Development in the People's Republic of China”. It has been included in the newly published plan (2001-2005) "to build Shanghai international shipping center".

The Central Committee of the Party indicated in 1994: the building of Shanghai into an international shipping center is the key for the development of Pudong into an economic center in the Fareast and that of the whole Yangtze River Delta. The Shanghai international shipping center should take full advantage of the favorable

* Corresponding Author: li_liabin@126.com, 010-2316-0063

**1eesh@hhu.ac.kr 051)410-4404 
situations in the economic, financial and trade center of Shanghai, the Beilun deepwater port in Ningbo province, and the enormous container traffic in Shanghai and Jiangsu province to weave a system of ports with Shanghai as the center and with those in Zhejiang and Jiangsu provinces to coordinate.

However, there is also competition in this system of ports. Ningbo port has developed rapidly recent years. It has continued to expand at a very high average annual growth rate of approximately $31 \%$ over the period 1997-2007 and it has become the eighth largest container port in the world in 2007. As a nearby port with Shanghai port, the competition can't be avoided during the high-speed development. This paper will aim to the space structure of Shanghai International Shipping Center, and also research the attraction of Shanghai port and Ningbo port for cargo resources in Zhejiang Province to analysis its port competitiveness. The purpose of this study is to provide Ningbo International Port Group with suggestion of development strategy and forecast the trend in development of Ningbo port.

\section{A Comparative Analysis of Ports in the Yangtze River}

\subsection{Overview of Shanghai International Shipping Center}

As one of the mainland China's traditional industrial centers, Shanghai has drawn worldwide attention. As shown in figure1, the throughput of Shanghai container port has dramatically developed since the reform (or 'opening up') of the mainland China's economy began in 1978.

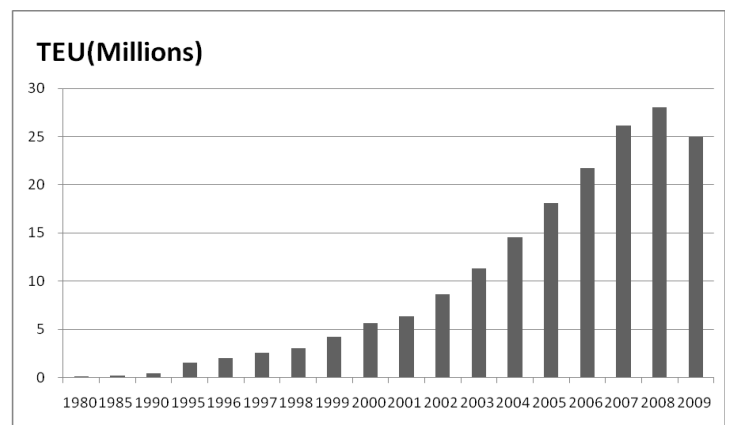

Source: Constructed by author using information from various sources

Fig. 1 Historic throughput at Shanghai Port

A more recent picture of container throughput at both Shanghai and Ningbo container ports (see figure2) reveals that the phenomenal growth of Shanghai's international container throughput has continued. It also shows, however, that the port of Ningbo now poses a significant threat to Shanghai's position as the leading container port on the central eastern seaboard of mainland China. As can be seen in the graph, the (largely international) container throughput to the hinterlands of the two ports has continued to expand at a very high average annual growth rate of approximately $31 \%$ over the period 1997-2009. In addition, the graph reveals that Ningbo's market share of the two ports' total international container throughput has been consistently increasing over this period, at the expense of Shanghai.

By inspection of the comparative annual growth rates in throughput at the two ports over the period 1998-2009, we are able to gain some insights as to why this has been the case. Figure3 clearly shows the vastly superior growth at Ningbo compared to Shanghai over this period. Given its lower base in terms of the absolute level of throughput, however, this is not a wholly unexpected result.

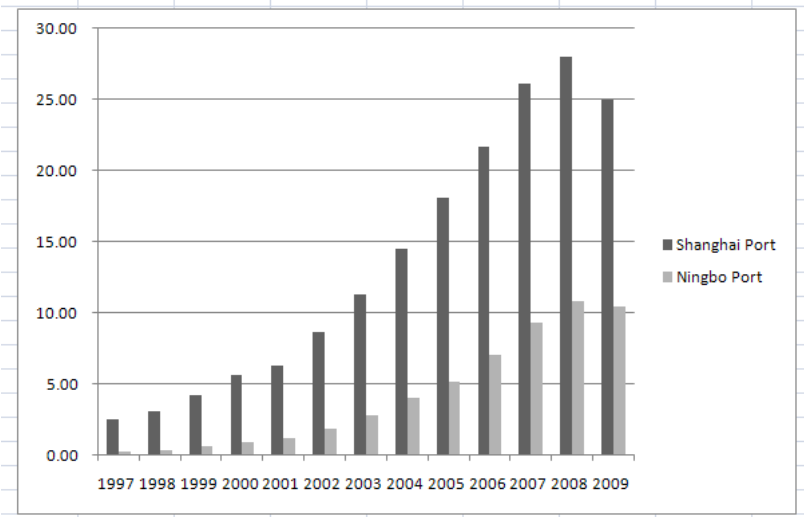

Source: Constructed by author using information from various sources Fig. 2 Recent container throughput for Shanghai port and Ningbo port

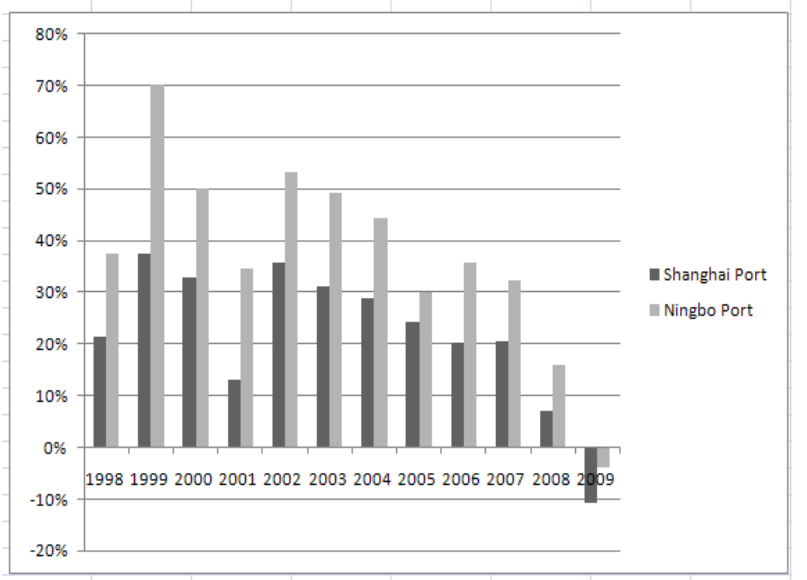

Source: Constructed by author using information from various sources Fig. 3 Recent annual growth rates in container throughput for Shanghai and Ningbo port 
Jia-bin $\mathrm{Li} \cdot \mathrm{Su}-\mathrm{Ho}$ Lee

In 2007, Ningbo achieved a great annual increase in container throughput. Spurred on by a tremendous expansion in the industrial output of its natural hinterland of Zhejiang province, as well as by the fact that it is one of just four credible transshipment hubs in the Chinese mainland, Ningbo handled just over 9 million TEU. In consequence, in terms of throughput handled, it moved from being ranked 23 to 11 in the world league of container ports.

Port of Suzhou is an important inland river transport hub. It is situated in Jiangsu province. It consists of three ports in Zhangjiagang, Changshu and Taicang on the lower reaches of the Yangtze River. The total cargo throughput is about 127 million tons in 2006. It is the largest inland river port in China. The majority of the port trade is in coal, steel, and construction materials such as cement.

Port of Nanjing is the largest inland port in China, yearly throughput reaching 121.43 million tons in 2009. The port area is 98 kilometers in length and has 64 berths including 16 berths for ships with the tonnage of more than 10,000 . Nanjing is also the biggest container port along the Yangtze River; in March 2004, the one million container-capacity base, Longtan Containers Port Area opened, further consolidating Nanjing as the leading port in the region. In the 1960s the first Yangtze river bridge was completed, becoming almost the only solid connection between North and South in eastern China at the time. The bridge became a source of pride and an important symbol of modern China, having been built and designed by the Chinese themselves following the failed surveys by other nations and the reliance on and then rejection of Soviet expertise.

Begun in 1960 and opened to traffic in 1968, the bridge is a two-tiered road and rail design spanning 4,600 meters on the upper deck, with approximately 1,580 meters spanning the river itself.

Wenzhou Port lies on the southeast coast of China with Ningbo Port to the north and Fuzhou Port to the south. In the southeast, Kaohsiung and Keelung of Taiwan are separated by the sea. It is located in the Economic Delta of Yangtze River which is led by Pudong, Shanghai. The port's coastline is 350-kilometre-long. With the superiority in geography, Wenzhou Port is one of the 25 main coastal ports of China and the center of offshore transportation and ocean shipping of southern Zhejiang Province, playing an important role in the integrated transportation system of China.

\subsection{The Competitiveness of Shanghai port and Ningbo port}

1) Natural condition

Ningbo Port is well situated in the middle of China's coastline, at the $\mathrm{T}$-shaped joining point of China's coastline and the Yangtze River. It's a famous deep-water port of mainland China. With deep water and smooth current, the port area of Ningbo is free from strong winds and waves. The entry channel is normally over 18.2 meters deep. Large ships of 250,000 up to 300,000 tonnages can come and leave at tide. With an exploitable deep-water coastline of over $120 \mathrm{~km}$, Ningbo Port owns broad developing and construction prospects. On the north of Beilun Port Area, Zhoushan Islands serve as its natural defense, so there is no need to build breakwaters when constructing berths at Beilun Port Area. Less investment can produce better benefits.

Ningbo ports have obvious advantages in depth of water which was the most important factor in port nature factors. According to the index of International Shipping Center, the depth of water should be more than -14 meters. The average water depth is about -9 meters in Shanghai before the construction of Yangshan deep sea port, the container vessels are limited seriously by it. The deep water factor is one of the comparative advantages of Ningbo port.

2) Price (direct cost to liner companies)

Port charges in mainland China are based very closely on a standard rate specified by China's Ministry of Communications. It includes separate charges for stevedoring, piloting and tugs. Currently Shanghai and Ningbo both adopt a more flexible pricing policy than sticking simply to the centrally set standard rates. Their approach is characterized by a differentiation between large and small customers, especially with respect to the stevedoring charge. Generally, large mainline operators receive a 10\% discount compared with coastal liner operators. The stevedoring charges listed in Table1 and it shows that it is the same at the two ports.

Table 1 Stevedoring charges in Shanghai and Ningbo's container terminals in RMB

\begin{tabular}{|l|c|c|c|}
\hline & 20GP & 40GP & $40 \mathrm{HQ}$ \\
\hline $\begin{array}{l}\text { Terminals in } \\
\text { Shanghai }\end{array}$ & 370 & 560 & 560 \\
\hline Terminals in Ningbo & 370 & 560 & 560 \\
\hline
\end{tabular}

The piloting tariffs are all based on a standard rate by Ministry of Communications. For distances less than 10 nautical miles, the rate is $0.5 \mathrm{RMB}$ per net ton. For any distance above 10 nautical miles, the rate for the rest of the 
voyage is $0.005 \mathrm{RMB}$ per net ton per nautical mile. Since the piloting distance for Ningbo is relatively shorter than for the terminals in Shanghai, especially STC, so the piloting charges payable in Ningbo are generally less than those prevailing in Shanghai

The tug tariffs for the ports of Shanghai and Ningbo are given in table 2 and table 3.

Table 2 Shanghai port tug tariff in RMB

\begin{tabular}{|l|c|c|c|c|c|c|}
\hline $\begin{array}{l}\text { Length of } \\
\text { vessel } \\
\text { (meters) }\end{array}$ & $\begin{array}{c}>22 \\
0\end{array}$ & $\begin{array}{c}180^{-} \\
220\end{array}$ & $\begin{array}{c}155^{-} \\
180\end{array}$ & $\begin{array}{c}122- \\
155\end{array}$ & $\begin{array}{c}95-1 \\
33\end{array}$ & $<95$ \\
\hline $\begin{array}{l}\text { Yangshan } \\
\text { port }\end{array}$ & 58600 & 45200 & 35200 & 33100 & 18400 & 17800 \\
\hline Waigaoqiao & 59200 & 48800 & 43500 & 34200 & 32600 & 27300 \\
\hline
\end{tabular}

Table 3 Ningbo port tug tariff in RMB

\begin{tabular}{|l|c|c|c|c|c|}
\hline $\begin{array}{l}\text { Length of } \\
\text { vessel } \\
\text { (meters) }\end{array}$ & $>320$ & $\begin{array}{c}251-3 \\
20\end{array}$ & $\begin{array}{c}171-2 \\
50\end{array}$ & $\begin{array}{c}121-1 \\
70\end{array}$ & $<120$ \\
\hline Ningbo port & 48760 & 39000 & 31620 & 22140 & 14700 \\
\hline
\end{tabular}

Stevedoring, piloting and tug charges are the three major port costs incurred in calling at a mainland Chinese port. Together, they account for about $90 \%$ of the total direct cost of a vessel's call at port. By broadly comparing the cost associated with the port calls of ships of similar size, it is self-evident that Ningbo possesses a definite price advantage.

\section{3) Informationization level}

Informationization level is also an important index of hub ports. The efficiency of port works could be increased by high informationization level. The informationization level depends on the implement condition of EDI.

Shanghai port has paid much attention to promote informatization and advanced equipments. The service objects of EDI platform are wide, which include government, port authority, liner, ship agent, cargo agent, tally company and so son. Especially in recent years, Shanghai has accelerated the construction of port infrastructure.

Comparatively speaking, although Ningbo port has started the development of EDI system, the coverage rate is much lower than in Shanghai port because of the backward equipments and it limit the further development of Ningbo port.

\section{Model setup}

\subsection{Shift-share analysis}

Shift-share analysis is one way to account for the competitiveness of a region's industries and to analyze the local economic base. This analysis is primarily used to decompose employment changes within an economy over a specific period of time into mutually exclusive factors, but it is also suitable to be used in research of the port traffic growth. Although shift-share analysis can't reflect the environmental change of internal competition in any container port cluster during a given period, it can divide the increase and decrease of variable into to parts ${ }^{--}$-share effect and shift effect. Share effect means the throughput of container port grows at the expected speed to remain its market share. In other words, it represents the average growth of the port cluster. Shift effect means gains or lost which a port got from other competitors in the same port cluster. The function of shift-share analysis may be considered generally as:

$$
\begin{aligned}
& A B S G R_{\mathrm{i}}=\text { TEU }_{i t_{1}}-\text { TEU }_{i t_{0}}=\operatorname{SHARE}_{i}+\operatorname{SHIFT}_{i} \\
& \text { SHARE }_{i}=\left(\frac{\sum_{i=1}^{n} T E U_{i t_{1}}}{\sum_{i=1}^{n} T E U_{i t_{0}}}-1\right) \bullet T E U_{i t_{0}} \\
& \operatorname{SHIFT}_{i}=A B S G R_{\mathrm{i}}-S H A R E_{i}
\end{aligned}
$$

where:

$A B S G R_{1}$ : Absolute increment of container throughput in portiduringtheperiodof $t_{0}$ tot $_{1}$.

$S H A R E_{1}$ : Share increment of container throughput in portiduringtheperiodof $t_{0}$ tot $_{1}$.

$T E U_{i t 1}$ : Container throughput in portiatt ${ }_{1}$.

$T E U_{i t 0}$ : Container throughput in portiatto.

$n$ : The number of ports in the port cluster.

We can get the information of competition between a port and other ports in the port cluster by calculating the net shift. It indicates that the competition level is high if the net shift between ports is high. This study will use the formula to measure the net shift as follow:

$$
V O L S H I F T=\frac{\sum_{i=1}^{n}\left|S H I F T_{i}\right|-\left|\sum_{i=1}^{n} S H I F T_{i}\right|}{2}
$$

Where,

VOLSHIFT: The shift increment between ports in a port 
cluster.

$n$ : The number of ports in the port cluster.

\subsection{Location quotient analysis}

The location quotient technique is the most commonly utilized economic base analysis method. It was developed in part to offer a slightly more complex model to the variety of analytical tools available to economic base analysts. This technique compares the local economy to a reference economy, in the process attempting to identify specializations in the local economy. The location quotient technique is based upon a calculated ratio between the local economy and the economy of some reference unit. In the research of regional economics, we used to calculate the relative concentration degree of an industry in a given area in order to measure the attraction for such industry in such area. Location quotient is an appropriate index and the function can be written as follow:

$$
L Q_{i j}=\frac{x_{i j} / \sum_{i} x_{i j}}{\sum_{j} x_{i j} / \sum_{i} \sum_{j} x_{i j}}
$$

Where,

$L Q_{i j}$ : The concentration degree of industry $\mathrm{i}$ in area $\mathrm{j}$.

$X_{i j}$ : The product of industry $\mathrm{i}$ in are $\mathrm{j}$.

$\sum_{i} x_{i j}:$ Gross product of area $\mathrm{j}$.

$\sum_{j} x_{i j}$ :Gross product of industry $\mathrm{i}$ in the big region or nation.

$\sum_{i} \sum_{j} x_{i j}$ : Gross product of the big region or nation.

Interpreting the Location Quotient is very simple. Only three general outcomes are possible when calculating location quotients. These outcomes are as follows:

\begin{tabular}{|l|l|l|}
\hline $\mathrm{LQ}<1.0$ & $\mathrm{LQ}=1.0$ & $\mathrm{LQ}>1.0$ \\
\hline
\end{tabular}

Suppose the LQ of a region or nation is 1 , it indicates that this department is specialized in the region or nation if the value of LQ is more than 1 . The greater the value of LQ is, the stronger the attraction for the industry in such area becomes.

In this study, hinterland location quotient model will be applied to analysis the port hinterland analysis, the model can be set up as follow:

$$
L P_{\mathrm{ij}}=\frac{h_{i j} / \sum_{i} h_{i j}}{\sum_{j} h_{i j} / \sum_{i} \sum_{j} h_{i j}}
$$

Where,

$L P_{i j}$ : Hinterland location quotient. It indicates the concentration ratio of cargoes in area $\mathrm{j}$ exported or imported through port I, which reflects the attraction of the port for the area.

$h_{i j}$ : The transshipment of cargoes in area $\mathrm{j}$ through port $\mathrm{i}$

$\sum_{i} h_{i j}$ : The total amount of cargoes in area $\mathrm{j}$.

$\sum_{j} h_{i j}$ : The total amount of cargoes transshipped through port $\mathrm{i}$ in the whole region

$\sum_{i} \sum_{j} h_{i j}$ : The total amount of cargoes in the whole region.

If the value of $L P_{i j}$ is more than 1, it shows cargo resources of area $\mathrm{j}$ are mainly transshipped through port $\mathrm{i}$. In other words, area $\mathrm{j}$ is hinterland of port $\mathrm{i}$. The greater the value of $L P_{i j}$ is, the stronger the attraction of port $i$ to area $\mathrm{j}$ becomes.

\section{Empirical analysis}

\subsection{Analysis of concentration ratio}

Every port belongs to a port cluster, so we should analyze the post's status in the port cluster it belongs to when we research the market share of port. In this study, shift-share model will be used to calculate the concentration according to the port's container throughput, and identify the role of every port in the Shanghai International Shipping Center.

1) The result of shift-share analysis

This study collected the container throughput of 12 ports in Shanghai International Shipping Center and calculated them by shift-share model. The result can be shown as table 3.

Shanghai port made a positive shift of 191.7 thousand TEU during the period of 2000-2004 and made a negative shift of 1154 thousand TEU over the period 2005-2009. On the other hand, Ningbo port made positive shift over both the period 2000-2004 and the period 2005-2009. The shift of Nanjing port, Nantong port, Suzhou port and Taichow port were negative during the both two periods. It indicates that the annual growth rate of container throughput in these ports is lower than the average level 
of the Shanghai International Shipping Center during the past decade. In addition, the net shift of the perid 2000-2004 was 445 thousand TEU and increased to 1567.7 thousand TEU during the period of 2005-2009. It shows the competition for cargo resources in the port cluster is getting more and more intense.

Table 3 Shift-Share analysis of ports in Shanghai International Shipping Center (Unit: 10,000 TEU)

\begin{tabular}{|c|c|c|c|c|c|c|}
\hline & \multicolumn{3}{|c|}{$2000-2004$} & \multicolumn{3}{|c|}{$2005-2009$} \\
\cline { 2 - 7 } & $\begin{array}{c}\text { Iet } \\
\text { increase }\end{array}$ & share & shift & $\begin{array}{c}\text { Iet } \\
\text { increase }\end{array}$ & share & shift \\
\hline Shanghai & 249.90 & 230.73 & 19.17 & 894.25 & 1009.60 & -115.40 \\
\hline Ningbo & 44.14 & 24.18 & 19.96 & 310.33 & 162.01 & 148.02 \\
\hline Nanjing & 0.78 & 22.53 & -21.75 & 28.40 & 36.52 & -8.12 \\
\hline Nantong & 7.08 & 13.18 & -6.10 & 10.54 & 32.74 & -22.20 \\
\hline Zhenjiang & 1.90 & 2.88 & -0.99 & 10.58 & 10.29 & 0.29 \\
\hline Suzhou & 1.75 & 16.33 & -14.58 & 28.03 & 35.44 & -7.41 \\
\hline Zhoushan & 0.08 & 0.00 & 0.08 & 2.98 & 3.54 & -0.56 \\
\hline Yangzhou & 0.98 & 0.00 & 0.99 & 10.99 & 3.80 & 7.18 \\
\hline Wenzhou & 2.68 & 2.92 & -0.23 & 13.90 & 13.33 & 0.56 \\
\hline Jiangyin & 0.73 & 0.00 & 0.73 & 1.73 & 2.50 & -0.77 \\
\hline Taizhou & 3.63 & 0.00 & 3.63 & 1.67 & 0.66 & 1.20 \\
\hline Taichow & 0.43 & 1.30 & -0.86 & 1.90 & 4.22 & -2.32 \\
\hline Total & 314.08 & 314.05 & 0.05 & 1315.30 & 1314.65 & 0.47 \\
\hline Net Shifts & \multicolumn{3}{|c|}{44.5} & & 156.77 & \\
\hline
\end{tabular}

The conception of future container port system in Shanghai International Shipping Center is based on the research of O'Mahony (1998). As shown in the figure 4, Shanghai port will become the only hub port in the Yangtze River Delta. Ningbo port will take advantage of its harbor depth to attract big container ships and become a large deep-sea direct-call port.

The other conception of future container port system in Shanghai International Shipping Center is based on the research of Starr (1944) about twin hub container ports in a port cluster. As shown in figure 5, there will be two hub ports in the Shanghai International Shipping Center. Shanghai port will increase the T/S proportion to $50 \%$ by the development and utilization of Yangshan deep water port. At the same time, Ningbo port attract big container ships by using its competitive advantage of natural condition and improving the port service level, and become another hub port of the port cluster. This study is tending to support the Starr's view. In other words, we guess that Ningbo Port will become a hub port of the Shanghai International Shipping Center and compete with Shanghai port fiercely.

\subsection{Location quotient analysis}

According to the research above, we can guess that twin hub ports (Shanghai port and Ningbo port) will appear in the Shanghai port, Ningbo port's hinterland is confined in Zhejiang Province. So in this part, we aim to the change process of the two ports' competitiveness in Zhejiang Province.

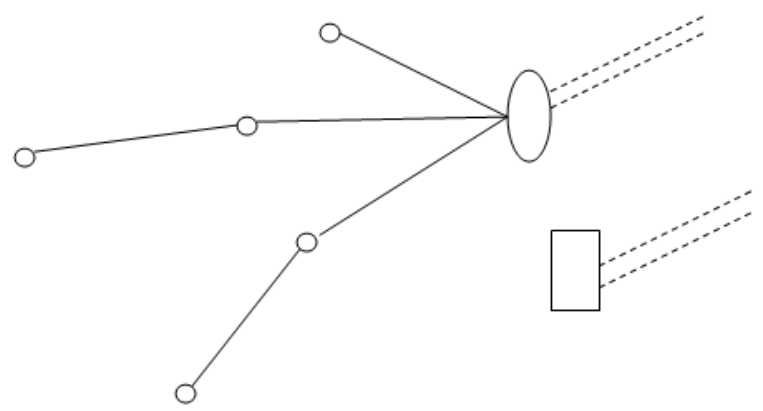

Fig. 4 The conception of one hub port system

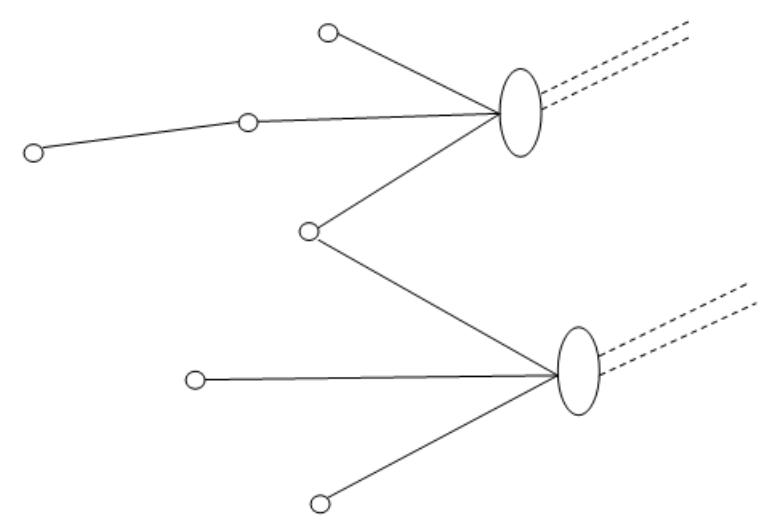

Fig. 5 The conception of twin hub port system

The data of cargoes flow direction during the period 2005-2009 are collected and calculated by using Location quotient model. The result and analysis are as follow.

1) Location quotient of the two ports in 2005

The two ports' competitiveness in cities of Zhejiang Province in 2005 are shown in table 4.

Table 4 Location quotient of the two ports in 2005

\begin{tabular}{|c|c|c|c|c|c|c|}
\hline & \multicolumn{3}{|c|}{ Shanghai port } & \multicolumn{3}{c|}{ Ningbo port } \\
\hline & Import & Export & Average & Import & Export & Average \\
\hline Zhangzhou & 1.46 & 1.39 & 1.43 & 0.35 & 0.34 & 0.34 \\
\hline Wenzhou & 0.20 & 0.70 & 0.45 & 0.09 & 0.87 & 0.48 \\
\hline Jiaxing & 2.11 & 1.55 & 1.83 & 0.09 & 0.05 & 0.07 \\
\hline Huzhou & 2.34 & 1.52 & 1.93 & 0.00 & 0.16 & 0.08 \\
\hline Shaoxing & 0.62 & 1.13 & 0.88 & 0.83 & 0.76 & 0.80 \\
\hline Jinhua & 1.01 & 1.21 & 1.11 & 0.51 & 0.67 & 0.59 \\
\hline Quzhou & 0.98 & 1.10 & 1.04 & 0.00 & 0.33 & 0.16 \\
\hline Zhoushan & 0.31 & 0.43 & 0.37 & 0.75 & 1.59 & 1.17 \\
\hline Lishui & 0.20 & 0.86 & 0.53 & 0.00 & 1.39 & 0.65 \\
\hline Taichow & 0.36 & 0.50 & 0.43 & 0.53 & 1.94 & 1.24 \\
\hline Ningbo & 0.19 & 0.46 & 0.33 & 2.82 & 2.13 & 2.47 \\
\hline
\end{tabular}


In terms of import, Ningbo port only has strong attraction for cargoes in Ningbo when Shanghai port has strong attraction for cargoes in Hangzhou, Jiaxing, Huzhou and Jinhua. In terms of export, cargoes in Ningbo, Zhoushan, Lishui and Taichow are mainly exported through Ningbo port and cargoes in Hangzhou, Jiaxing, Huzhou and Jinhua choose Shanghai port. The result of average value shows Ningbo port has strong attraction for cargoes in Ningbo, Zhoushan and Taichow. In other words, the three regions are direct hinterland of Shanghai port. However, Hangzhou, Jiaxing, Huzhou and Shaoxing are Shanghai port's direct hinterland in 2005.

2) Location quotient of the two ports in 2006

The two ports' competitiveness in cities of Zhejiang Province in 2006 are shown in table 5. In terms of import, Ningbo port only has strong attraction for cargoes in Ningbo when Shanghai port has strong attraction for cargoes in Hangzhou, Jiaxing, Huzhou, Jinhua and LIshui. In terms of export, cargoes in Ningbo, Zhoushan, Lishui, Wenzhou and Taichow are mainly exported through Ningbo port and cargoes in Hangzhou, Jiaxing, Huzhou, Shaoxing Quzhou and Jinhua choose Shanghai port. The result of average value shows Ningbo port has strong attraction for cargoes in Ningbo and Taichow. In other words, the two regions are direct hinterland of Shanghai port. However, Hangzhou, Jiaxing, Huzhou, Jinhua, Quzhou and Shaoxing are Shanghai port's direct hinterland in 2006.

Table 5 Location quotient of the two ports in 2006

\begin{tabular}{|c|c|c|c|c|c|c|}
\hline & \multicolumn{3}{|c|}{ Shanghai port } & \multicolumn{3}{c|}{ Ningbo port } \\
\hline & Import & Export & Average & Import & Export & Average \\
\hline Zhangzhou & 1.45 & 1.44 & 1.45 & 0.36 & 0.33 & 0.35 \\
\hline Wenzhou & 0.26 & 0.71 & 0.49 & 0.15 & 1.02 & 0.59 \\
\hline Jiaxing & 2.34 & 1.62 & 1.98 & 0.05 & 0.07 & 0.06 \\
\hline Huzhou & 2.30 & 1.62 & 1.96 & 0.03 & 0.11 & 0.07 \\
\hline Shaoxing & 0.96 & 1.11 & 1.03 & 0.96 & 0.86 & 0.91 \\
\hline Jinhua & 1.15 & 1.54 & 1.35 & 0.42 & 0.75 & 0.59 \\
\hline Quzhou & 1.23 & 1.10 & 1.16 & 0.00 & 0.59 & 0.29 \\
\hline Zhoushan & 0.12 & 0.33 & 0.23 & 0.32 & 1.58 & 0.95 \\
\hline Lishui & 2.32 & 0.82 & 1.57 & 0.15 & 1.39 & 0.77 \\
\hline Taichow & 0.56 & 0.50 & 0.53 & 0.65 & 1.83 & 1.24 \\
\hline Ningbo & 0.27 & 0.48 & 0.37 & 2.29 & 1.92 & 2.11 \\
\hline
\end{tabular}

3) Location quotient of the two ports in 2007

The two ports' competitiveness in cities of Zhejiang Province in 2007 are shown in table 6 .

In terms of import, Ningbo port only has strong attraction for cargoes in Ningbo and Shaoxing when Shanghai port has strong attraction for cargoes in Hangzhou, Jiaxing, Huzhou, Jinhua and LIshui. In terms of export, cargoes in Ningbo, Zhoushan, Lishui, Wenzhou and Taichow are mainly exported through Ningbo port and cargoes in Hangzhou, Jiaxing, Huzhou, Shaoxing Quzhou and Jinhua choose Shanghai port. The result of average value shows Ningbo port has strong attraction for cargoes in Ningbo, Zhoushan, Shaoxing and Taichow. In other words, the four regions are direct hinterland of Shanghai port. However, Hangzhou, Jiaxing, Huzhou, Lishui, Jinhua, Quzhou and Shaoxing are Shanghai port's direct hinterland in 2007.

Table 6 Location quotient of the two ports in 2007

\begin{tabular}{|c|c|c|c|c|c|c|}
\hline & \multicolumn{3}{|c|}{ Shanghai port } & \multicolumn{3}{c|}{ Ningbo port } \\
\hline & Import & Export & Average & Import & Export & Average \\
\hline Zhangzhou & 1.30 & 1.46 & 1.38 & 0.38 & 0.34 & 0.36 \\
\hline Wenzhou & 0.36 & 0.78 & 0.57 & 0.18 & 1.08 & 0.63 \\
\hline Jiaxing & 2.77 & 1.72 & 2.25 & 0.07 & 0.08 & 0.07 \\
\hline Huzhou & 1.90 & 1.69 & 1.80 & 0.00 & 0.13 & 0.07 \\
\hline Shaoxing & 0.95 & 1.16 & 1.06 & 1.29 & 0.83 & 1.07 \\
\hline Jinhua & 1.33 & 1.03 & 1.18 & 0.44 & 0.91 & 0.68 \\
\hline Quzhou & 0.90 & 1.17 & 1.03 & 0.12 & 0.57 & 0.35 \\
\hline Zhoushan & 0.82 & 0.28 & 0.55 & 0.60 & 1.65 & 1.12 \\
\hline Lishui & 2.93 & 0.77 & 1.85 & 0.00 & 1.31 & 0.65 \\
\hline Taichow & 0.32 & 0.47 & 0.40 & 0.64 & 1.78 & 1.21 \\
\hline Ningbo & 0.25 & 0.46 & 0.36 & 2.12 & 1.80 & 1.96 \\
\hline
\end{tabular}

4) Location quotient of the two ports in 2008

The two ports' competitiveness in cities of Zhejiang Province in 2008 are shown in table 7.

Table 7 Location quotient of the two ports in 2008

\begin{tabular}{|c|c|c|c|c|c|c|}
\hline & \multicolumn{3}{|c|}{ Shanghai port } & \multicolumn{3}{c|}{ Ningbo port } \\
\hline & Import & Export & Average & Import & Export & Average \\
\hline Zhangzhou & 1.28 & 1.44 & 1.36 & 0.45 & 0.30 & 0.37 \\
\hline Wenzhou & 0.48 & 0.74 & 0.61 & 0.18 & 1.20 & 0.69 \\
\hline Jiaxing & 2.81 & 1.84 & 2.32 & 0.11 & 0.07 & 0.09 \\
\hline Huzhou & 1.89 & 1.77 & 1.83 & 0.00 & 0.11 & 0.05 \\
\hline Shaoxing & 1.17 & 1.18 & 1.17 & 1.28 & 0.84 & 1.06 \\
\hline Jinhua & 0.85 & 1.06 & 0.96 & 0.31 & 0.92 & 0.62 \\
\hline Quzhou & 0.94 & 1.26 & 1.10 & 0.40 & 0.66 & 0.53 \\
\hline Zhoushan & 0.60 & 0.27 & 0.43 & 0.18 & 1.56 & 0.87 \\
\hline Lishui & 0.95 & 0.73 & 0.84 & 0.12 & 1.37 & 0.75 \\
\hline Taichow & 0.28 & 0.44 & 0.36 & 0.59 & 1.80 & 1.20 \\
\hline Ningbo & 0.29 & 0.44 & 0.36 & 2.02 & 1.82 & 1.92 \\
\hline
\end{tabular}

In terms of import, Ningbo port only has strong attraction for cargoes in Ningbo and Shaoxing when Shanghai port has strong attraction for cargoes in Hangzhou, Jiaxing, Huzhou, Quzhou and Shaoxing. In terms of export, cargoes in Ningbo, Zhoushan, Lishui, Wenzhou and Taichow are mainly exported through Ningbo port and cargoes in Hangzhou, Jiaxing, Huzhou, Shaoxing Quzhou and Jinhua choose Shanghai port. The result of average value shows Ningbo port has strong 
attraction for cargoes in Ningbo, Shaoxing and Taichow. In other words, the four regions are direct hinterland of Shanghai port. However, Hangzhou, Jiaxing, Huzhou, Jinhua, Quzhou and Shaoxing are Shanghai port's direct hinterland in 2008.

5) Location quotient of the two ports in 2009

The two ports' competitiveness in cities of Zhejiang Province in 2009 are shown in table 8.

In terms of import, Ningbo port only has strong attraction for cargoes in Ningbo and Shaoxing when Shanghai port has strong attraction for cargoes in Hangzhou, Jiaxing, Huzhou, Quzhou and Shaoxing. In terms of export, cargoes in Ningbo, Zhoushan, Lishui, Wenzhou and Taichow are mainly exported through Ningbo port and cargoes in Hangzhou, Jiaxing, Huzhou, Shaoxing Quzhou and Jinhua choose Shanghai port. The result of average value shows Ningbo port has strong attraction for cargoes in Ningbo, Shaoxing and Taichow. In other words, the four regions are direct hinterland of Shanghai port. However, Hangzhou, Jiaxing, Huzhou, Jinhua, Quzhou and Shaoxing are Shanghai port's direct hinterland in 2009.

Table 8 Location quotient of the two ports in 2009

\begin{tabular}{|c|c|c|c|c|c|c|}
\hline & \multicolumn{3}{|c|}{ Shanghai port } & \multicolumn{3}{c|}{ Ningbo port } \\
\hline & Import & Export & Average & Import & Export & Average \\
\hline Zhangzhou & 1.35 & 1.44 & 1.39 & 0.47 & 0.30 & 0.38 \\
\hline Wenzhou & 0.43 & 0.72 & 0.57 & 0.11 & 1.22 & 0.67 \\
\hline Jiaxing & 3.14 & 1.92 & 2.53 & 0.06 & 0.07 & 0.06 \\
\hline Huzhou & 1.99 & 1.85 & 1.92 & 0.00 & 0.09 & 0.04 \\
\hline Shaoxing & 0.93 & 1.22 & 1.08 & 1.37 & 0.81 & 1.09 \\
\hline Jinhua & 1.59 & 1.03 & 1.31 & 0.55 & 0.90 & 0.73 \\
\hline Quzhou & 1.31 & 1.19 & 1.25 & 0.54 & 0.79 & 0.66 \\
\hline Zhoushan & 0.83 & 0.38 & 0.61 & 0.26 & 1.29 & 0.77 \\
\hline Lishui & 0.42 & 0.67 & 0.55 & 0.11 & 1.41 & 0.76 \\
\hline Taichow & 0.34 & 0.38 & 0.36 & 0.54 & 1.85 & 1.19 \\
\hline Ningbo & 0.30 & 0.42 & 0.36 & 1.87 & 1.79 & 1.83 \\
\hline
\end{tabular}

6) The result of the two ports over recent 5 years

The two ports' competitiveness in cities of Zhejiang Province during the period 2005-2009 are shown in table 9. It is easy to draw a conclusion that Hangzhou, Jiaxing, Huzhou, Jinhua and Quzhou are Shanghai port's direct hinterland in Zhejiang Province. In other words, most of cargoes in the regions above mentioned prefer Shanghai port to other ports. Ningbo, Taichow and Zhoushan are Ningbo port's direct hinterland in Zhejiang Province. Cargoes in Shaoxing are mainly exported or imported through neither Shanghai port nor Ningbo port in 2005 . However, it became the common direct hinterland of both Shanghai port and Ningbo port. It indicates that the competition of the two ports in Shaoxing is very intensely. Wenzhou and Lishui are not the direct hinterland of neither Shanghai port nor Ningbo port.

Table 9 Average location quotient of the two ports over recent 5 years

\begin{tabular}{|c|c|c|c|c|c|c|}
\hline & & 2005 & 2006 & 2007 & 2008 & 2009 \\
\hline \multirow{2}{*}{ Hangzhou } & Shanghai port & 1.43 & 1.44 & 1.38 & 1.36 & 1.39 \\
\cline { 2 - 7 } & Ningbo port & 0.34 & 0.35 & 0.36 & 0.37 & 0.38 \\
\hline \multirow{2}{*}{ Wenzhou } & Shanghai port & 0.45 & 0.49 & 0.57 & 0.61 & 0.57 \\
\cline { 2 - 7 } & Ningbo port & 0.48 & 0.59 & 0.63 & 0.69 & 0.67 \\
\hline \multirow{2}{*}{ Jiaxing } & Shanghai port & 1.83 & 1.98 & 2.25 & 2.32 & 2.53 \\
\cline { 2 - 7 } & Ningbo port & 0.07 & 0.06 & 0.07 & 0.09 & 0.06 \\
\hline \multirow{2}{*}{ Huzhou } & Shanghai port & 1.93 & 1.96 & 1.80 & 1.83 & 1.92 \\
\cline { 2 - 7 } & Ningbo port & 0.08 & 0.07 & 0.07 & 0.05 & 0.04 \\
\hline \multirow{2}{*}{ Jhaoxing } & Shanghai port & 0.88 & 1.03 & 1.06 & 1.17 & 1.08 \\
\cline { 2 - 7 } & Ningbo port & 0.80 & 0.91 & 1.07 & 1.06 & 1.09 \\
\hline \multirow{2}{*}{ Quzhou } & Shanghai port & 1.11 & 1.35 & 1.18 & 0.96 & 1.31 \\
\cline { 2 - 7 } & Ningbo port & 0.59 & 0.59 & 0.68 & 0.62 & 0.73 \\
\cline { 2 - 7 } & Shanghai port & 1.04 & 1.16 & 1.03 & 1.10 & 1.25 \\
\hline \multirow{2}{*}{ Zhoushan pingbo port } & 0.16 & 0.29 & 0.35 & 0.53 & 0.66 \\
\cline { 2 - 7 } & Shanghai port & 0.37 & 0.23 & 0.55 & 0.43 & 0.61 \\
\cline { 2 - 7 } Ningbo port & 1.17 & 0.95 & 1.12 & 0.87 & 0.77 \\
\hline \multirow{2}{*}{ Lishui } & Shanghai port & 0.53 & 1.57 & 1.85 & 0.84 & 0.55 \\
\cline { 2 - 7 } & Ningbo port & 0.65 & 0.77 & 0.65 & 0.75 & 0.76 \\
\hline \multirow{2}{*}{ Ningbo } & Shanghai port & 0.43 & 0.53 & 0.40 & 0.36 & 0.36 \\
\cline { 2 - 7 } & Ningbo port & 1.24 & 1.24 & 1.21 & 1.20 & 1.19 \\
\cline { 2 - 7 } & Nhanghai port & 0.33 & 0.37 & 0.36 & 0.36 & 0.36 \\
\hline \multirow{2}{*}{ Ningbo port } & 2.47 & 2.11 & 1.96 & 1.92 & 1.83 \\
\hline
\end{tabular}

\section{Conclusions}

The conclusion of this study include two aspects, one is status in the Shanghai International Shipping Center of Shanghai port and Ningbo port, the other is the competition of hinterland in Zhejiang Province between the two ports which shows the partition of the hinterland of them in Zhejiang Province.

\subsection{Twin hub container ports model}

Shift-share analysis model are used to analyze container throughput of the 8 main ports in the Shanghai International Shipping Center. The conclusion is as follow:

By analyzing the container throughput of the Shanghai International Shipping Center using shift-share analysis, we can find that Shanghai port's growth speed is faster than the speed of the whole port cluster during the period 2000-2004, but slower than it from 2005 to 2009. But the 
growth rate of Ningbo port is higher than it of the port cluster. So Ningbo port is not impossible to be another hub port in the Yangtze River Delta according to this trend.

\subsection{Partition of the hinterland in Zhejiang Province.}

The following conclusions are reached based on the location quotient analysis: 1) Hangzhou, Jiaxing, Huzhou, Jinhua and Quzhou are direct hinterland of Shanghai port in Zhejiang Province. 2) Ningbo, Taichow and Zhoushan are direct hinterland of Ningbo port in Zhejiang Province. Especially Ningbo and Taichow, most cargoes of the two cities above mentioned are exported or imported by Ningbo port. 3) The container volume of Shaoxing is relatively big in Zhejiang Province. Now it is the common direct hinterland of both Shanghai port and Ningbo port. 4) Most of cargoes in Wenzhou choose Wenzhou port or port in the delta of the Pearl River. So it is neither hinterland of Shanghai port nor hinterland of Ningbo port. 5) The cargo volume of Lishui is small because of its backward economy. It is not the direct hinterland of the two ports until now. But with the development of economy, it will become a direct hinterland of Ningbo port gradually.

\section{Reference}

[1] Buckmann, E and Veldman, S.(2000): "A model on container port competition." SIG-2 International Workshop, Genoa.

[2] Hu Liang De. (2005), The analysis of the market of Yangtze River container transport, China Ports.

[3] Hayuth, Y. (1993), "Port Competition and Regional Port Cooperation"in Haezendonck (2001) Essays on Strategy Analysis for Seaports, Garant, Louvain: Belgium.

[4] Heaver, T.D. (1995), "The implications of increased competition among ports for port policy," Maritime Policy and Management, Vol.22, No.2, pp.125-133.

[5] Liu Jun, "Yangshan Port open to the world," Shanghai Exchange Bulletin, 2006.1.17

[6] National Bureau of Statistics of China (2005), "2004 China Statistical Yearbook", China Statistics Press.

[7] O’Mahony. (1998), "Opportunities for container port: a cargo system report," London: Cargo system, 1998

[8] Song, "Regional container port competition and co-operation: the case of HongKong and South China", Journal of Transport Geography, Vol.10, pp.99 -110.

[9] Wang, J. J. (1998), “A Container Load Center with a Developing Hinterland: A Case Study of Hong Kong”,
Journal of Transport Geography, Vol. 6, No. 3, pp. $187-200$.

Received 2 August 2010

Revised 24 September 2010

Accepted 27 September 2010 